\title{
A Probe into the Necessity of Personalized Employment Guidance in the Chinese Institutions of Higher Education
}

\author{
Tan Ju-hua ${ }^{1}$ \\ ${ }^{1}$ Centre of Employment Guidance, Jiangxi Normal University, Nanchang, China \\ Correspondence: Tan Ju-hua, Lecturer in the Centre of Employment Guidance, Jiangxi Normal University, \\ Nanchang 330022, China. Email: cn-popularproducts@hotmail.com
}

Received: August 28, 2013 Accepted: October 9, 2013 Online Published: November 22, 2013

doi:10.5539/hes.v3n6p46

URL: http://dx.doi.org/10.5539/hes.v3n6p46

\begin{abstract}
Owning to the economic recession, the Chinese college graduates are suffering greater pressure in finding jobs than before. For this reason, a research was carried out at Jiangxi Normal University to investigate the current employment situation of the Chinese college graduates. Data were collected by way of questionnaires, interviews and symposiums. SPSS17.0 software was used as the tool to analyze the collected data. Data analysis shows that only a few of the college graduates interviewed were optimistic about their job prospects and anxiety prevailed. Therefore, personalized employment guidance, which has the advantage of taking into consideration the specific needs of each student, is recommended as an effective way of facilitating employment in the Chinese institutions of higher education.
\end{abstract}

Keywords: employment, personalized guidance, college graduates

As the situation of obtaining employment is becoming increasingly rigorous in China, the Chinese college graduates are suffering much greater pressure in finding jobs in 2013. For this reason, the Chinese Ministry of Education specifically issued the notice on making good preparations for guiding employment in the Chinese institutions of higher education in 2013. According to this notice, the grim employment situation has occurred for the following reasons. Firstly, the economic foundation is far from being sound, which brings about employment pressure at the national level across China. Secondly, there are 6990000 graduates in 2013, with an increase of 190000 compared with 2012. Under the circumstances, employment guidance, which is an effective way of facilitating employment, is drawing more and more attention. To improve employment and competiveness, we need to give explicit answers to the following questions. "What kinds of guidance do the college students need?" "What is the present situation of employment guidance in the Chinese colleges?" "What are the effective ways of guiding employment?"

For this purpose, a research was carried out, aiming to find a special way of guiding employment for the Chinese college graduates. The special way of employment guidance was expected to be different from the conventional ones. And we took Jiangxi Normal University as an example.

Time: from the September of 2012 to the April of 2013

Method: questionnaire, interview and symposium

Tool: SPSS17.0 software

Subject: students of Grade 2009 from Jiangxi Normal University

Data analysis: data analysis shows that the research result was authentic, accurate and reliable, which means that it is representative of the current employment situation in the Chinese institutions of higher education in 2013.

In the research, 600 questionnaires were sent out, among which 566 valid ones were taken back, and the validity percentage amounted to $92 \%$. What's more, 10 symposiums were organized, each of which consisted of 30 students. And in-depth interviews were conducted with 20 students. 


\section{The Current Employment Situation of the Chinese College Graduates}

\subsection{Only a Few Were Optimistic about Their Job Prospects and Anxiety Prevailed}

When asked about their attitudes toward job prospects, $59.4 \%$ of them expressed their opinions in vague terms, $15.1 \%$ of them were pessimistic and only $23 \%$ of them were optimistic about their future jobs. Table 1 below gives us a clear picture.

Table 1. College students' attitudes toward job prospects

\begin{tabular}{lllll}
\hline & Frequency & Percentage & $\begin{array}{l}\text { Valid } \\
\text { Percentage }\end{array}$ & $\begin{array}{l}\text { Accumulated } \\
\text { Percentage }\end{array}$ \\
\hline Optimistic & 128 & 4.3 & 23.0 & 23.0 \\
Average & 330 & 11.0 & 59.4 & 82.4 \\
Pessimistic & 84 & 2.8 & 15.1 & 97.5 \\
Unclear & 14 & .5 & 2.5 & 100.0 \\
In total & 556 & 18.5 & 100.0 & \\
\hline
\end{tabular}

In the interviews, most of the students were found to be anxious about their forthcoming employment. However, their employment directions were not clear. This kind of anxiety even affected their life and study. For example, under the pressure of uncertain job prospect, a four-year female student who majored in computer science expressed a pessimistic view of life. For her, without a good job, it meant that she failed to live up to her parents' expectations. This sense of guilt stopped her from communicating with her family and greatly impaired her physical and psychological wellbeing.

\subsection{Ignoring the Diversity of Employment Channels and Not Good at Collecting Employment Information Actively}

Influenced by the traditional employment concepts, almost all the Chinese college graduates hope to find a stable and secure job, which used to be referred to as the "Iron Rice Bowl". This kind of thinking is well embodied in their employment values, that is, the property of the employing units has always been over-emphasized and the government offices, public institutions and large state-owned enterprises are favored. However, with the reform of the personnel system going on, the government offices and public institutions are in the process of streamlining bureaucracy, which results in a reduced demand for employees. At the same time, the deepening reform of the state-owned enterprises has also brought about a huge reduction in employing talents. Therefore, the shrinking job opportunities in the two public sectors have left many of the college graduates completely at a loss about what to do next.

As a matter of fact, the private sector is the largest employer in the job market now. However, adversely affected by a passion for the Iron Rice Bowl, many college graduates have neglected the job opportunities there. For them, they prefer staying unemployed to joining the ranks of the private sector. On the $16^{\text {th }}$ of April 2011, there was a job fair on campus at Jiangxi Normal University. At the job fair, more than 1000 graduates waited in line in front of the recruiting stands of the public schools, eager to submit their job applications. However, they showed an obvious bias against the private schools because few graduates submitted job applications to them. The recruiters of the private schools were greatly dismayed at this phenomenon.

According to my questionnaires, for those college graduates who were still unemployed, $39 \%$ of them were still preparing for their postgraduate entrance examinations, $19.9 \%$ of them had not found their ideal jobs yet, and only $15.9 \%$ of them failed to find any jobs at all. We can have a look at table 2 for a better understanding. 
Table 2. The reasons why the college graduates stayed unemployed

\begin{tabular}{lllll}
\hline & Frequency & Percentage & $\begin{array}{l}\text { Valid } \\
\text { Percentage }\end{array}$ & $\begin{array}{l}\text { Accumulated } \\
\text { Percentage }\end{array}$ \\
\hline Not found a job yet & 80 & 2.7 & 15.9 & 15.9 \\
$\begin{array}{l}\text { Preparing for postgraduate entrance } \\
\text { examination }\end{array}$ & 196 & 6.5 & 39.0 & 55.0 \\
Not found an ideal job yet & 100 & 3.3 & 19.9 & 74.9 \\
Resignation & 18 & .6 & 3.6 & 78.5 \\
Other reasons & 108 & 3.6 & 21.5 & 100.0 \\
In total & 502 & 16.7 & 100.0 & \\
\hline
\end{tabular}

During the process of our investigation, we found that the majority of the college graduates showed a mentality herd and had not established an overall understanding of the employment channels. That was why so many of them took the grueling postgraduate entrance examination. We also found that the college graduates obtained job information mainly from their college job guiding departments. Most of them were still waiting to be employed by the recruiters. Only a few of them were willing to take the initiative to go out, trying to find a job in the job market. As a matter of fact, very few of them recommended themselves to the employers. All these led to a very narrow job channel.

\subsection{Lacking Professional Values and Putting Immediate Interests before Long-Term Interests}

Due to the exorbitant cost of higher education and the relatively poor school days, salary, which has become the core professional value of modern college graduates, is being considered as the most important element in a job. Most of the college graduates suffered from great economic pressure in the course of job seeking. According to my questionnaires, about $60 \%$ of them relied on their parents for livelihood, which brought about much pressure to them.

Table 3. The main economic sources of college graduates

\begin{tabular}{lllll}
\hline & Frequency & Percentage & $\begin{array}{l}\text { Valid } \\
\text { Percentage }\end{array}$ & $\begin{array}{l}\text { Accumulated } \\
\text { Percentage }\end{array}$ \\
\hline Savings & 42 & 1.4 & 8.0 & 8.0 \\
Parents & 310 & 10.3 & 59.2 & 67.2 \\
Scholarship & 16 & .5 & 3.1 & 70.2 \\
Part-time jobs & 56 & 1.9 & 10.7 & 80.9 \\
Borrowed money & 12 & .4 & 2.3 & 83.2 \\
Others & 88 & 2.9 & 16.8 & 100.0 \\
In total & 524 & 17.4 & 100.0 & \\
\hline
\end{tabular}

My questionnaire analysis also showed that about $80 \%$ of the college graduates valued material comforts. For this reason, they would like to find a job in the developed areas such as the big cities instead of the under-developed areas such as the western part of China and the rural areas. They feared challenge. In terms of employment mentality, they were always in a hesitant and negative state of mind. Faced with choices, they were eager to make the quick buck, ignoring their long-term career development.

College graduate employment is such a complicated issue that employment guidance has always been recognized as the best way of solving this thorny problem. And it is drawing more and more attention too. As a matter of fact, employment guidance does play an important role in facilitating employment and has helped 
many graduates find a job. However, its late start in China resulted in lack of specialization and experience. The drawbacks in the current employment guidance system make it fail to meet the needs of the graduate employment.

\section{The Current Situation of Graduate Employment Guidance in the Chinese Institutions of Higher Education}

In China, college graduate employment guidance started in the 1980s. With the development of the marketing economy, employment guidance was getting more and more attention because talent utilization and development had become bottlenecks for the Chinese economical development. Since China ended its job assignment system for the college graduates in 1997, all the college graduates have been entering the job market for a job. It was since then that employment guidance began to be paid much attention to. However, it mainly provided help in the form of advice and suggestions. It set up a bridge between the graduates and the employers and helped to solve the employment problem to some extent. Plenty of defects still exist in such an employment guidance system, they are as follows.

\subsection{Prominent Contradiction between Supply and Demand}

A survey was carried out about the causes of college graduates' employment difficulty among 13825 young people in Jiangxi Province in 2010 and a white paper was released thereafter. According to the statistics of the survey, $9.1 \%$ of them thought that the employment difficulty arose from blocked employment information channels; $10.3 \%$ of them thought that the college graduates lacked correct employment outlooks and aimed too high; $8.3 \%$ of them thought that the college graduates were not independent enough; $9.0 \%$ of them thought that the employment policies were not good and reasonable enough; $9.9 \%$ of them thought that the college graduates were not qualified enough for the job market; $9.4 \%$ of them thought that the government, employers and the colleges did not communicate with each other enough. The above problems leading to employment difficulty are the primary ones which need to be solved by employment guidance.

Table 4. The causes of college graduates' employment difficulty

\begin{tabular}{lll}
\hline & Number & Percentage \\
\hline Less job opportunities than before & 2122 & $14.3 \%$ \\
Too fastidious employers & 1448 & $9.8 \%$ \\
Unfair competition & 1699 & $11.5 \%$ \\
Blocked job information channels & 1356 & $9.1 \%$ \\
Personnel system still lagging behind & 1249 & $8.4 \%$ \\
Unsound or unreasonable job policies & 1334 & $9.0 \%$ \\
Unqualified talent training & 1471 & $9.9 \%$ \\
$\begin{array}{l}\text { Serious dependent mentality } \\
\text { Too high expectations }\end{array}$ & 1237 & $8.3 \%$ \\
$\begin{array}{l}\text { Lack of communication between the graduates, } \\
\text { the government and the employers }\end{array}$ & 1527 & $10.3 \%$ \\
$\begin{array}{l}\text { Data source: The white paper of the employment situation } \\
\text { of young people in Jiangxi Province in 2010 }\end{array}$ & 1382 & $9.4 \%$ \\
\hline
\end{tabular}

The above table indicates that employment guidance is in urgent need to correct the students' backward concepts of employment. It is only in this way that the unhealthy employment thinking can be put right and the graduates' competitiveness can be improved in the job market. From the table below, we can see that $23.2 \%$ of the college graduates did not get any help from any agencies or organizations. Only $27.6 \%$ of them were helped by the school employment guiding departments. This suggests that although employment guidance courses have been popularly established, they do not work effectively. Especially, the absence of suitable remedies for each 
individual college graduate has greatly discounted the effectiveness of these courses.

Table 5. Help obtained by the college graduates while finding a job

\begin{tabular}{lllll}
\hline & Frequency & Percentage & $\begin{array}{l}\text { Valid } \\
\text { Percentage }\end{array}$ & $\begin{array}{l}\text { Accumulated } \\
\text { Percentage }\end{array}$ \\
\hline No help at all & 106 & 3.5 & 23.2 & 23.2 \\
Basic organizations of the CCP & 52 & 1.7 & 11.4 & 34.6 \\
Labor departments & 80 & 2.7 & 17.5 & 52.2 \\
School employment departments & 126 & 4.2 & 27.6 & 79.8 \\
Community organizations & 16 & .5 & 3.5 & 83.3 \\
Business, taxation and finance & 50 & 1.7 & 11.0 & 94.3 \\
departments & 12 & .4 & 2.6 & 96.9 \\
Youth League organizations & 12 & .2 & 1.3 & 98.2 \\
Reunion of fellow-provincials & 6 & .3 & 1.8 & 100.0 \\
Others & 8 & 15.1 & 100.0 & \\
In total & 456 & & & \\
\hline
\end{tabular}

Table 5 shows that an acute contradiction exists between the supply and demand in the area of college employment guidance. Supply is far from enough to meet the need of the demand.

\subsection{Not Specialized and Specific Enough}

Undoubtedly, college students are in need of employment guidance. However, those interviewed reported that they received only limited employment instruction. Some instruction was even useless. Many instructors lacked professional training themselves and they just relied on personal experience or pure employment theory to carry out their vacuous instructional work. In the employment guidance classes, most instructors indulged in imparting theoretical knowledge. Specific guidance was very limited when it came to the level of concrete operation and practice. Most instructors emphasized the importance of self-awareness. Only a small portion of them provided the students with one-to-one vocational assessment. All in all, although the majority of the colleges stress the importance of career planning, they have not offered specific guidance in connection with individual career planning yet. With the gradual increase of their individuation and individuality, the students, who become more concerned with individualized matters, need more personalized guidance.

\subsection{Not Diversified Enough and Poor in Content}

According to our survey, employment guidance in the Chinese colleges today is mainly implemented in the form of classes and lectures. Its content is restricted to imparting general employment knowledge. This kind of employment guidance, which may benefit all the audiences in the classes and lectures, can't be very effective, because it can only solve employment problems at surface. As we all know, it is impossible to solve a college graduate's employment problem just by attending classes and lectures. This type of problem should be supplied with intensive follow-up service and dealt with in depth systematically. What's more, the flow of employment information in the classes and lectures is not adequate and quick enough to balance the information asymmetry between the employers and the college graduates.

Career choice should be combined with individual character. The conventional employment guidance usually takes the form of class teaching, which makes it impossible to further analyze and evaluate each student's career interest, character, ability and job value. However, it is on the basis of these factors that a career choice can be made. Thus we can say that the homogeneous employment guidance can not ensure individual career evaluation and fails to help the students to make a reasonable job choice.

As a continuous process, college graduates' employment guidance forms an important part of ideological education on campus in China. Its aim is to aid each student to make a correct career choice. For a college 
graduate, it is a big leap for him to go to the workplace. Thus, an accurate understanding of the society, upon which he can make his career planning effectively, is the key to his transformation from school life to social life, and to his future career success as well. Therefore, in order to carry out their work efficiently, it is especially important for the relevant departments to explore new and effective ways of guiding employment.

\section{Personalized Guidance as a Necessary Complement to the Employment Guidance System in the Chinese Institutions of Higher Education}

Owning to its special nature, the emerging personalized employment guidance can act as a necessary complement to the conventional employment guidance system. It can be used as an effective way to tackle the problems existing in the conventional employment guidance system. To have a better understanding of personalized employment guidance, we can refer to Frank Parsons. As the father of vocation guidance, Frank Parsons (1909) developed a framework to help individuals decide on a career in his major work, Choosing a Vocation. This framework contained a three part formulation.

1. First, a clear understanding of yourself, aptitudes, abilities, interests, resources, limitations, and other qualities

2. Second, a knowledge of the requirements and conditions of success, advantages and disadvantages, compensations, opportunities, and prospects in different lines of work

3. Third, true reasoning of the relations of these two groups of facts (Parsons, 1909, p. 5)

According to Parsons, ideal career choices are based on matching personal traits (aptitude, abilities, resources, personality) with job factors (wages, environment, etc.) to produce the best conditions of vocational success. Parson's framework later became the basis of the contemporary trait/factor theory of career development.

Based on the universal employment guidance to all the college graduates, personalized guidance requires extra specific one-to-one counseling service to be provided to each individual. In this way, each student's need can be satisfied to promote his/her individualized development. The advantages of personalized employment guidance are as follows.

\subsection{Deeper Level of Guidance and More Specific}

Personalized employment guidance, which consists of more than thirty items, can be classified as the following eight aspects, transaction management, information supply, policy guidance, skill training, psychological counseling, decision consulting, career planning and quality improving. In terms of employment procedure and policy system guidance, personalized employment guidance can offer better service according to each student's specific need, whereas in terms of job-seeking training skill, psychological counseling and job decision-making, it demonstrates its superiority because it takes each student's individuation into consideration. According to the records of the employment guidance room at Jiangxi Normal University, personalized counseling focused on job choice decision-making and job-seeking skills. In these two respects, many students asked for one-to-one guidance, which was considered to be more specific. In terms of employment psychology adjustment, students from different grades all considered one-to-one guidance to be more humanized because their privacy can be well protected.

\subsection{More Systematic Guidance Process and Broader Range}

Personalized employment guidance is better suited to tracking service because it is supposed to provide the students with counseling service during their four-year study. At the first year, the focus is on career prospects, which associates each student's major with its future job requirements and job opportunities. During the second and the third year, the students accumulate professional knowledge and learn vocational skills. At this stage, they should build their knowledge structures and receive proper skill training according to the need of the society. The fourth year is the key stage for job-seeking. Therefore, guidance should be available in terms of employment policy and job-seeking skills. For some college students, psychological counseling should be offered to help them transform from a student to a social being. Personalized employment guidance is not only aimed at individuals, but also takes into account the common problems of all the college graduates. Besides, teaching and education reforms, which aim to better foster the all-round development of the students, can be pushed directly or indirectly by the feedback received from each college graduate while he/she is seeking a job.

\subsection{More Considerate of Autonomy and More Humanized}

The aim of personalized employment guidance is to inspire each student to know about his/her potential, on the basis of which he/she can make a career plan according to the goal of life. In this way, each student's individuality can be well protected to aid his/her further career development. If we let the students use the testing 
software and the relevant scales to gauge their career possibilities and encourage them to make career choices according to the testing results in combination with their interests and abilities, we can say that this is just the start of personalized employment guidance. The value of personalized employment guidance lies in not only fully respecting each student's individuality, but also making each student realize the dignity of humanity and occupation as well as the objective differences between each person. It not only provides service to each student's unique career development, but also tries to convince him/her of finding the "true self" through emotional communication.

By means of personalized employment guidance, an instructor makes heart-to-heart exchanges of views with the students, which can often tap into the deep souls of them. Guidance in this kind, which is often thought to be enlightened, embodies a type of humanistic care. Each person is unique, which means that he/she has his/her special qualities. The key part of personalized employment guidance is to take into consideration each student's uniqueness, on the basis of which their individual characteristics can be respected. This kind of respect is equivalent to a kind of true care for the students and it embodies human nature.

\section{Conclusion}

Personalized employment guidance can take the form of telephones, internet and face-to-face communication. It helps the students to find a solution to their problems on the basis of equal communication and consultation. It is a kind of heuristic educational method. Psychological puzzles often arise from individual differences. Under the circumstances, personalized guidance can help the relevant student better understand himself/herself, which results in mental health and psychological adaptability. Because it provides employment directions to each student in a scientific way, personalized employment guidance satisfies the diverse needs of the students at different levels. As a matter of fact, owing to its important position in employment guidance work, personalized employment guidance has become a trend and objective that each institution of higher education in China is striving for.

\section{References}

Cao, X.-Y. (2008). Problems in College Students' Career Planning and Approaches to Them. Education Exploration, 10, 136-137.

Parsons, F. (1909). Choosing a vocation. Boston: Houghton Mifflin.

Schein, E, H. (1987). Individuals and Careers. In J. Lorsch (Ed.), Handbook of Organizational Behavior. Englewood Cliffs, NJ: Prentice-Hall.

Schmidt, J. J. (2003). Counseling in schools: Essential services and comprehensive programs (4th ed.). Boston: Allyn and Bacon.

Shen, Z.-Q. (2006). On the cultivation of college students' innovative ability. Journal of Hangzhou Business Institute, 1 .

Studer, J. R. (2005). The professional school counselor: An advocate for students. Belmont, CA: Thomson Brooks/Cole.

Zhang, J.-D. (2007). Exploration on College Students' Career Planning. Ascert, 6, 173-175.

Zunker, V. G. (2002). Career Counseling: Applied concepts for life planning (6th ed.). Pacific Grove, CA: Brooks/Cole.

\section{Copyrights}

Copyright for this article is retained by the author(s), with first publication rights granted to the journal.

This is an open-access article distributed under the terms and conditions of the Creative Commons Attribution license (http://creativecommons.org/licenses/by/3.0/). 